Purdue University

Purdue e-Pubs

2014

\title{
A Free-Particles-Based Technique for Boiling Heat Transfer Enhancement in a Wetting Liquid
}

T.Y. Kim

Purdue University

J.A. Weibel

Purdue University, jaweibel@purdue.edu

S V. Garimella

Purdue University, sureshg@purdue.edu

Follow this and additional works at: http://docs.lib.purdue.edu/coolingpubs

Kim, T. Y.; Weibel, J. A.; and Garimella, S V., "A Free-Particles-Based Technique for Boiling Heat Transfer Enhancement in a Wetting Liquid" (2014). CTRC Research Publications. Paper 224.

http://dx.doi.org/http://dx.doi.org/10.1016/j.ijheatmasstransfer.2013.12.070

This document has been made available through Purdue e-Pubs, a service of the Purdue University Libraries. Please contact epubs@purdue.edu for additional information. 


\title{
A free-particles-based technique for boiling heat transfer enhancement in a wetting liquid
}

\author{
Tae Young Kim* ${ }^{*}$ Justin A. Weibel, and Suresh V. Garimella ${ }^{\dagger}$ \\ Cooling Technologies Research Center, an NSF IUCRC \\ School of Mechanical Engineering, Purdue University \\ 585 Purdue Mall, West Lafayette, IN 47907-2088 USA
}

\begin{abstract}
An easy-to-implement technique for pool boiling heat transfer enhancement is proposed and evaluated through an experimental investigation. This free-particle technique brings about nucleate boiling at a low degree of superheat by means of metal particles that are not fixed to the heated surface, but rather are free to move with respect to the surface. The effects of copper particles with sizes ranging from tens of nanometers to $9 \mathrm{~mm}$ on nucleate boiling heat transfer and critical heat flux (CHF) of the wetting dielectric fluid FC-72 are investigated. Visualizations of the bubble nucleation characteristics due to the free particles are presented. Experimental results show that the introduction of microscale free particles onto a superheated surface effectively facilitates bubble nucleation and thus increases the nucleate boiling heat transfer coefficients. Millimeter-sized as well as nanoscale free particles do not have a strong effect on the boiling heat transfer performance of this wetting fluid. Introduction of a large quantity of microscale free particles reduces CHF by increasing the resistance to liquid replenishment and vapor departure; however, by properly selecting particle size and quantity, an improvement in both nucleate boiling heat transfer and $\mathrm{CHF}$ is observed. For the case where $0.2 \mathrm{~g}$ of $10 \mu \mathrm{m}$-diameter free particles are placed on a polished copper surface, corresponding to a particle layer thickness of approximately $67 \mu \mathrm{m}$, the average nucleate boiling heat transfer coefficient is enhanced by $76.3 \%$ over the heat flux range of 10 to $159 \mathrm{~kW} / \mathrm{m}^{2}$, while CHF is increased by $10 \%$.
\end{abstract}

Keywords: Phase change, free particles, wetting fluid, FC-72, nucleation, pool boiling, heat transfer enhancement

\footnotetext{
* Currently with Korea Institute of Machinery \& Materials.

${ }^{\dagger}$ Corresponding author, Phone: 765-494-5621, sureshg@purdue.edu
} 


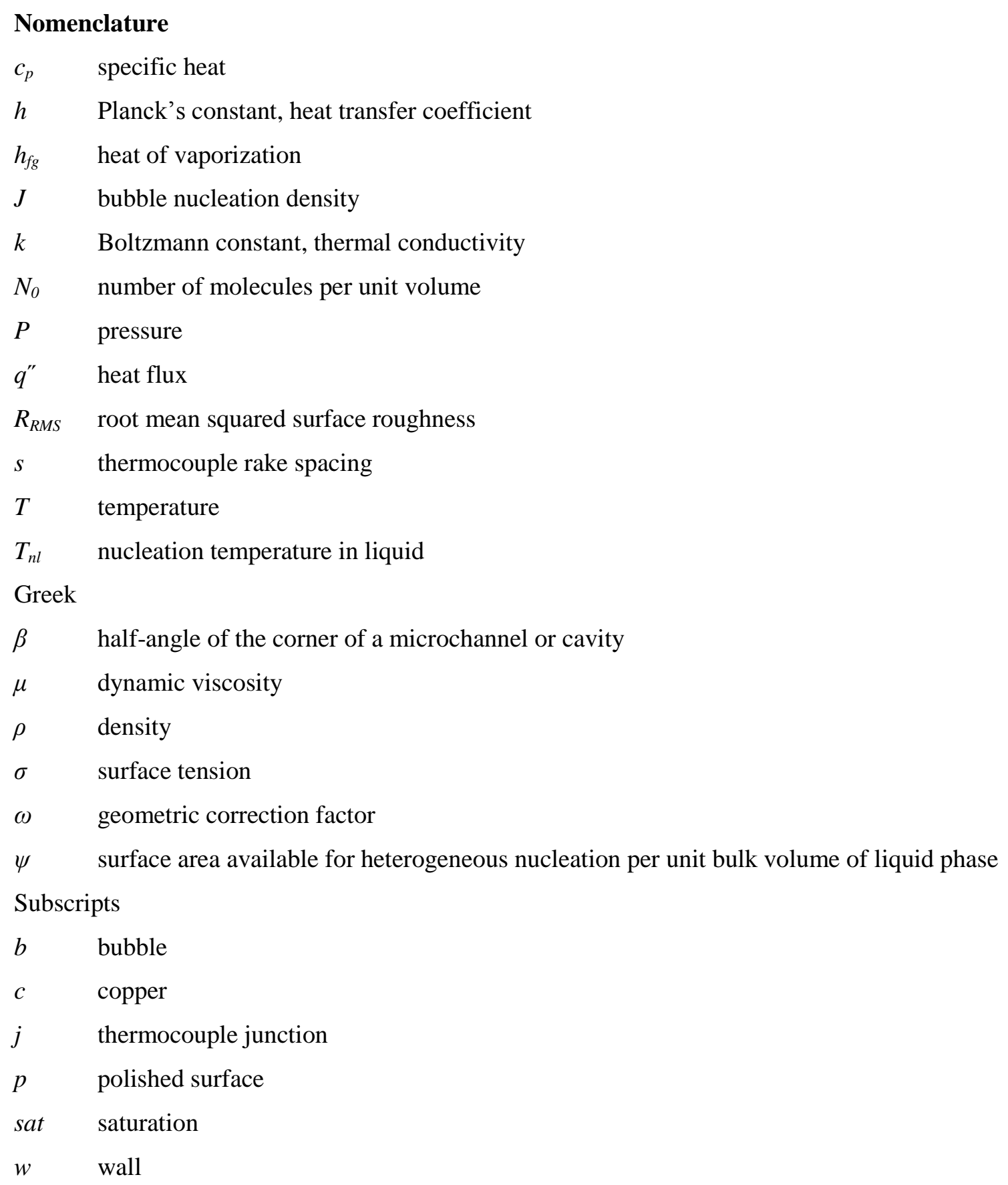




\section{Introduction}

It is well known that surface treatments may provide effective boiling heat transfer enhancement, and many variants of treated surfaces have been developed. Most surface treatments may be categorized as attached promoters, roughened surfaces, or fluid additives. The typical mechanisms by which surface treatment techniques enhance boiling heat transfer include provision of preferential nucleation sites on the heated surface, or alteration of the physical properties of the working fluid.

Attached promoters have been among the most widely used surface treatment methods since Milton improved nucleate boiling heat transfer by sintering a porous layer of thermally conductive particles onto tube surfaces in the 1960s [1]. There are numerous recent studies on such structures. Liter and Kaviany [2] proposed a modulated porous layer coating, with periodically non-uniform feature thicknesses and shapes, designed to reduce the liquid-vapor counterflow resistance and improve critical heat flux (CHF). You et al. [3] and O'Connor and You [4] reduced the incipient superheat, improved nucleate boiling, and increased CHF by depositing a microstructured layer consisting of particles, a carrier, and a binder on a heated surface through spraying and painting methods, respectively. Parker and El-Genk $[5,6]$ studied nucleate boiling of the dielectric liquids HFE-7100 and FC-72 from porous graphite layers containing randomly interconnected microscale pores; their measurements showed improved heat transfer performance compared to a flat copper surface. In addition to these studies, boiling heat transfer in various porous structures has been characterized through experimental, numerical, and theoretical investigations [7-11].

Besides particulate layers, wire mesh and pin-fin type attached promoters have also been evaluated. $\mathrm{Li}$ and Peterson [12] investigated sintered copper wire screens of varying thickness, volumetric porosity, and mesh size to determine the dependence of boiling performance on these geometric parameters. Wei and Honda [13] fabricated microscale square pin-fin structures through a dry etching process to improve the boiling behavior of FC-72 from silicon chips. Rainey and You [14]demonstrated significantly higher FC-72 boiling heat transfer coefficients compared to smooth pin fins by coating the pin-fin array with a second-tier microporous layer. The primary role of attached promoters is to decrease the incipient and nucleate boiling superheats by providing an increased number of readily-activated nucleation sites on the heated surface. However, only a limited number of previous studies, including those cited above, have investigated attached promoter performance for a range of porous topologies (e.g., feature size and porosity), which could be used as a basis for boiling performance optimization. Rather, many of the studies have focused on development of fabrication methods for the attached promoters.

Surface roughening has also garnered attention as a relatively simple, cheap, and effective method for boiling heat transfer enhancement. Jakob [15], who first studied the effect of surface roughness on the 
boiling of water, found that a surface with a square grid of machined grooves improved boiling heat transfer by approximately $300 \%$ compared to a smooth surface. Similar conclusions were reached by other researchers who used emery paper [16] and electrical discharge machining (EDM) [17] as surface roughening methods. A wide variety of fluids have been investigated for surfaces with various degrees of roughness, all showing that the cavities generated during roughening processes serve as nucleation sites $[18,19]$. Since the shape of cavities on roughened surfaces is the primary determinant of their role as nucleation sites, reentrant cavities were proposed and shown to serve as more stable nucleation sites due to the reversed curvature of the liquid-vapor interface within the cavity [20]. While roughened surfaces have been shown to enhance boiling, the increased performance has often been seen to decrease with time due to surface aging. Jakob [15] and Corty and Foust [21] observed this performance degradation, and reported that surface corrosion and oxidation hinder the long-term reliability of surface roughening.

Another boiling heat transfer enhancement approach uses fluid additives, such as by seeding with a small concentration of nanoscale particles to produce a nanofluid. The heat transfer behavior of nanofluids has been intensively studied by many researchers since the late 1990s. Most studies have focused on the change in heat transfer characteristics using different types of nanoscale particles, e.g., metal oxides [22-24] and carbon nanotubes [25,26]. While nanofluids are simple to implement from an application and fabrication perspective, their influence on the nucleate boiling heat transfer coefficient is insignificant compared to the other surface enhancement techniques discussed above. The only improvement typically realized is an increase in CHF due to alteration of the surface wettability by roughening [22-24]. While an increase in nucleate boiling heat transfer due to nanofluids was observed in a few studies [26,27], other researchers reported deterioration of nucleate boiling heat transfer due to nanoparticles in solution [22] or no change at all [28]. Nanoparticle-coated surfaces [29] have been shown to improve $\mathrm{CHF}$, but without improvement in nucleate boiling heat transfer.

In this paper, a novel free-particle boiling heat transfer enhancement technique is proposed and its effect is evaluated using the wetting dielectric fluid FC-72 as the working fluid. An important practical advantage of this technique is that it is comparatively easier to implement than particle sintering, brazing, or other exotic fabrication methods. This makes it possible to readily study the quantitative effects of the size and number of particles as experimental variables on the nucleate boiling heat transfer performance. In this study, copper particles ranging from tens of $\mathrm{nm}$ to $9 \mathrm{~mm}$ were used as the free particles. This represents a wider range of boiling enhancement feature sizes than previously investigated in a single study.

\section{Free-particle boiling enhancement}


Using the free-particle technique, boiling heat transfer is improved through placement of particles that are free to move onto the heated surface. The key mechanism for boiling heat transfer enhancement by free particles is to provide active nucleation sites on the surface, similar to conventional surface enhancement methods. Li and Cheng [30] described the heterogeneous bubble nucleation density using classical kinetics of nucleation [31,32] as

$$
J_{h e t}=N_{0}^{2 / 3} \psi\left(\frac{k T_{n l}}{h}\right) \exp \left\{-\frac{16 \pi \sigma^{3} \omega}{3 k T_{n l}\left(P_{b}-P_{l}\right)^{2}}\right\}
$$

where $\omega$ is the geometric correction factor for the minimum work required to form a critical nucleus. This correction factor depends on the contact angle for the solid-liquid interface, $\theta$, and the half-angle of the corner of a cavity, $\beta$, and can be expressed as

$$
\omega=\frac{\beta}{2 \pi}(1+\cos \theta)^{2}(2-\cos \theta) .
$$

For microchannels with triangular, rectangular, and trapezoidal cross-sectional areas, the values of $2 \beta$ at the channel corners are $60^{\circ}, 90^{\circ}$, and $120^{\circ}$, respectively. Due to the presence of the corner geometry, the incipient superheat is decreased compared to a flat surface. As reported in the literature [2,5,7,11,33-35], a decrease in the incipient boiling superheat for surfaces coated with sintered particle layers is attributed to corner cavities formed where the particles attach to the heated surface.

The concept of the free-particle technique comes from the idea that boiling heat transfer is primarily affected by local geometric features of the surface, and less so by the actual attachment of particles. In this study, copper particles are chosen because they can be obtained in a range of sizes, and the density of copper makes them resistant to removal from the surface (due to buoyant forces exerted by the departing vapor) even at the higher heat fluxes. Free particles that remain settled on the heated surface thus form narrow corner cavities which serve to increase the active nucleation sites by decreasing the geometric correction factor in Eq. (1), and enhance boiling heat transfer.

A preliminary experiment was performed to demonstrate the basic concept of the free-particle technique by showing the influence of free particles on boiling of FC-72. In Fig. 1, free particles of copper of diameter 149-440 $\mu \mathrm{m}$ are placed on the left half of a uniformly heated copper surface, while the right side is maintained clean of particles. At the heat flux of $10 \mathrm{~kW} / \mathrm{m}^{2}$ shown, the free particles bring about nucleate boiling on the left half of the surface, while natural convective heat transfer is dominant on the right half. As viewable in the associated movie made available as Supplementary Data, several microscale particles intermittently depart from the left half of the surface due to the rising vapor bubbles, but a majority of the particles remain on the surface, and continue to provide nucleation sites. 
The boiling heat transfer performance improvement due to the presence of free particles can be optimized by varying the number and size of the particles. Increasing the number of particles placed on the heated surface would be expected to increase the probability of formation of cavities between the free particles and the surface, resulting in a larger number of nucleation sites, and therefore a higher heat transfer coefficient. However, a larger number of particles may restrict replenishment of the bulk working liquid to the nucleation sites, and thus decrease CHF. Based on Eq. (1) and the classical kinetics of nucleation, increasing the size of the free particles reduces the superheat required for bubble nucleation, but fewer particles can be used over the same projected surface area, decreasing the overall nucleation site density. Due to this clear trade-off, an optimum particle size that maximizes the boiling heat transfer performance is expected to exist. In the present work, the boiling heat transfer is characterized as a function of the number and size of free particles used, and optimal values are identified.

\section{Experimental setup and procedures}

A schematic diagram of the pool boiling test setup is shown in Fig. 2. The top $25.4 \mathrm{~mm} \times 25.4 \mathrm{~mm}$ test surface of a copper heater block is in contact with the liquid bath. The polished mirror-finish surface has roughness, $R_{R M S}$, of $25 \mathrm{~nm}$ as measured by a non-contact, $3 \mathrm{D}$, scanning white light interferometer (NewView 6200, Zygo Corp.). Each copper heater block has 12 holes on its underside for insertion of $25.4 \mathrm{~mm}$ long cartridge heaters, and 8 holes tapped into the sides of the block for centerline thermocouple temperature measurements. The copper heating block is inserted into a housing made of PEEK $(k=0.28$ $\mathrm{W} / \mathrm{m} \cdot \mathrm{K})$. An alumina silicate ceramic $(k=1.6 \mathrm{~W} / \mathrm{m} \cdot \mathrm{K})$ is inserted between the copper and PEEK to insulate the four sides of the heating block, and is chosen because it can withstand higher temperatures than PEEK. Another block made of the same ceramic is positioned beneath the copper heating block with 12 holes to allow feed-through of the cartridge heaters. A bottom PEEK housing is attached to the heater assembly with screws, and shrouds the ceramic blocks to further reduce heat loss to the ambient.

A $6.35 \mathrm{~mm}$ high polycarbonate square annulus, with a $27.4 \mathrm{~mm} \times 27.4 \mathrm{~mm}$ pocket at its center, is sealed by compression to the top of the heater assembly. A chamfer in the PEEK around the perimeter of the test surface forms a shallow gap for sealing the heater assembly seam exposed to the test fluid. As shown in the magnified view in Fig. 2, a layer of RTV sealant is placed in the gap and allowed to cure for 90 minutes in an oven at $75{ }^{\circ} \mathrm{C}$, followed by application of an epoxy (3M DP-190) to fill the remaining gap. Four $92.7 \mathrm{~mm}$ high polycarbonate walls are aligned on top of the shorter polycarbonate square annulus and sealed by compressing a PTFE gasket. A cover plate is sealed to the top of the polycarbonate walls by another gasket, and forms a $27.4 \mathrm{~mm} \times 27.4 \mathrm{~mm} \times 99.1 \mathrm{~mm}$ chamber that confines working fluid and the free particles on the heated surface. The polycarbonate is transparent to allow for visualization at 
$30 \mathrm{fps}$ with a digital camera (Lumix DMC-LX5, Panasonic). The assembled test setup is placed in an oven at $75^{\circ} \mathrm{C}$ for 2 hours to cure the epoxy layer around the sample edge. The curvature on the short polycarbonate wall forms a smooth meniscus in the epoxy layer around the edge of the test surface, and prevents premature, unintended activation of nucleation sites at the edge prior to incipience of boiling on the surface itself.

Prior to testing, an additional cartridge heater is positioned at the center of the chamber cover plate to be used as a liquid pool heater for the degassing process. A $3.175 \mathrm{~mm}$ diameter stainless steel condenser tube is wound in a coil in the vapor space (not shown in Fig. 2). During testing, a chilled water-glycol (50\%-50\%) mixture flows through the stainless steel tube to condense the working fluid vapor. A chiller (Neslab ULT-80) cycles the water-glycol mixture at a flow rate of $0.5 \mathrm{l} / \mathrm{min}$ and maintains the mixture at a temperature of $16^{\circ} \mathrm{C}$ throughout the degassing process and the experiment. A $6.35 \mathrm{~mm}$ polyurethane tube connects the liquid pool to a vapor trap. The flow rate and temperature of the condenser liquid are selected to ensure that no working fluid is observed to collect in the vapor trap during the experiment (to prevent fluid loss from the chamber over time). The vapor trap is open to ambient; therefore, the pressure of the liquid pool is maintained at atmospheric pressure during testing. At saturation under these conditions, FC-72 has the following thermophysical properties: $T_{s a t}=56^{\circ} \mathrm{C}, \rho=1594 \mathrm{~kg} / \mathrm{m}^{3}, \mu=4.3 \times 10^{-}$ ${ }^{4} \mathrm{~kg} / \mathrm{m} \mathrm{s}, k=0.054 \mathrm{~W} / \mathrm{m} \mathrm{K}, h_{f g}=88 \mathrm{~kJ} / \mathrm{kg}, c_{p}=1101 \mathrm{~J} / \mathrm{kg} \mathrm{K}$, and $\sigma=0.010 \mathrm{~N} / \mathrm{m} \mathrm{[36]}$.

The 12 imbedded cartridge heaters in the copper block are powered to provide the desired heat input. Eight thermocouples are embedded along the centerline of the copper block to measure the temperature profile. The inset in Fig. 2 shows the location of thermocouples in the copper heating block. An additional thermocouple is placed $15 \mathrm{~mm}$ above the heated surface to measure the pool reference temperature. The temperature measurements are logged to a data acquisition system (Agilent 34970A) and are processed in LabVIEW to calculate the heat flux, $q^{\prime \prime}$, imposed at the surface, and the corresponding wall temperature, $T_{\mathrm{w}}$. The T-type thermocouples are referenced to a dry block ice-point (Omega TCR-III) with a junction temperature measured by a resistance temperature detector (RTD). Since all thermocouples are referenced to a single ice-point junction, and were simultaneously calibrated against the same stable temperature source (Omega CL122-4), uncertainty in temperature differences is $\pm 0.1{ }^{\circ} \mathrm{C}$. The absolute uncertainty in the temperature measurements is $\pm 0.3{ }^{\circ} \mathrm{C}$. Based on the uniform thermocouple spacing, the local wall temperatures are calculated as follows:

$$
\begin{aligned}
& T_{w 2}=T_{j 6}-\frac{T_{j 5}-T_{j 6}}{3} \\
& T_{w 3}=T_{j 8}-\frac{T_{j 7}-T_{j 8}}{3}
\end{aligned}
$$


In an analogous manner, $T_{w l}$ is calculated based on the temperature gradient calculated through linear regression of temperature measurements at $j 1, j 2, j 3$, and $j 4$. Assuming heat transfer occurs from the top surface of the heater block uniformly, the average wall temperature, $T_{w}$, is calculated on an area-averaged basis as

$$
T_{w}=\frac{9}{25} T_{w 1}+\frac{16}{25}\left(\frac{T_{w 2}+T_{w 3}}{2}\right) .
$$

The local and average heat fluxes are also calculated based on the thermocouple rakes as follows:

$$
\begin{aligned}
& q_{1}^{\prime \prime}=-k_{c}\left(\frac{d T}{d s}\right)_{(j 1-j 4)} \\
& q_{2}^{\prime \prime}=-k_{c} \frac{1}{3 s}\left(T_{j 6}-T_{j 5}\right) \\
& q_{3}^{\prime \prime}=-k_{c} \frac{1}{3 s}\left(T_{j 8}-T_{j 7}\right) \\
& q^{\prime \prime}=\frac{9}{25} q_{1}^{\prime \prime}+\frac{16}{25}\left(\frac{q_{2}^{\prime \prime}+q_{3}^{\prime \prime}}{2}\right)
\end{aligned}
$$

While local deviations in the boiling heat transfer mechanisms are occasionally observed on the test surface, the copper block does not propagate temperature non-uniformities to the thermocouple rake locations, which record near-uniform heat flux and extrapolated surface temperatures for all test cases. Based on the quoted temperature measurement uncertainties, and using standard propagation of error analysis, the area-averaged wall temperature and heat flux uncertainties are approximately $\pm 0.2{ }^{\circ} \mathrm{C}$ and \pm 4 $\mathrm{kW} / \mathrm{m}^{2}$ over the range of heat fluxes investigated.

To perform a test, the pool is initially filled with $45 \mathrm{ml}$ of FC-72. A degassing procedure is conducted by boiling the working fluid using the pool heater for at least 2 hours prior to every experiment. To reduce the liquid level beneath the condenser coil following degassing so that the liquid pool temperature does not become stratified during testing, the working fluid is drained using a syringe until $25 \mathrm{ml}$ remains in the pool. For free particle test cases, the chamber cover is briefly removed and the desired copper particles are gently introduced into the test chamber to avoid scratching the surface. After degassing, the heat flux supplied by the cartridge heaters is increased in steps to obtain the boiling curve. The thermocouple temperature data is collected when steady-state conditions are satisfied at each discrete heat flux increment. Steady-state operation is assumed to have been reached when the time-averaged variation of the wall superheat temperature, acquired every 3 seconds, is less than $0.0003{ }^{\circ} \mathrm{C} / \mathrm{s}$ for 150 seconds. Despite the chaotic movement of the free particles that occurs within the fluid during boiling, the area-averaged surface temperature and heat flux still reach repeatable steady-state conditions per this 
definition. Once steady-state conditions are satisfied, time-averaged temperature data are obtained from 30 measurements collected over 90 seconds, and are used to calculate the actual surface heat flux and the corresponding wall superheat as described above. This procedure is repeated until critical heat flux is identified based on a sharp increase in the wall superheat for a small increment of heat flux. To better resolve this transition, the heat flux is increased in small increments $\left(\sim 2-3 \mathrm{~kW} / \mathrm{cm}^{2}\right)$ as $\mathrm{CHF}$ is approached for each test case.

Copper particles of 3,6, and $9 \mathrm{~mm}$ in diameter were obtained from Salem Specialty Ball Company. Each of these millimeter-sized particles is polished prior to the experiment in the same manner as the test surface. Nano- and microscale copper particles packed in an argon atmosphere were obtained from Alfa Aesar. A high-accuracy electronic scale (Ohaus Voyager) is used to control the weight of the particles placed on the heated surface. Table 1 shows the sizes, quantity, and estimated layer thickness of copper particles used in the experiments. The layer thickness is calculated by assuming that particles at the average diameter form an evenly distributed layer of close-packed spheres. If the quantity of particles used does not cover the entire surface, a percentage surface coverage area is provided in the table, and the layer thickness is reported to be equal to the average diameter.

\section{Results and discussion}

4.1 Effect of the size of free particles

In order to determine the effects of free-particle size on boiling of FC-72, experiments were conducted with different sets of copper particle sizes ranging from $20 \mathrm{~nm}$ to $3 \mathrm{~mm}$; boiling curves for these cases are presented in Fig. 3. As a baseline, results are also obtained for a polished surface without free particles. The heat transfer coefficients for all test cases are plotted as a function of heat flux in Fig. 4. The boiling curves are discussed in the following in order of decreasing particle size with the help of visualizations of the boiling process below.

For the polished surface, natural convection heat transfer occurs at low heat fluxes (below $20 \mathrm{~kW} / \mathrm{m}^{2}$ ), as visualized in Fig. 5 (a). The boiling curve for the polished surface in Fig. 3 does not indicate a noticeable temperature overshoot at the transition from the natural convection to the boiling regime. Following transition, the boiling curve is smooth, and the wall superheat consistently increases with increasing heat flux. The coverage area for nucleate boiling spreads as the heat flux increases, until boiling is observed over the entire heated surface area at a heat flux of $\sim 70 \mathrm{~kW} / \mathrm{m}^{2}$, as in the case shown in Fig. 5 (c). When the heat flux increases to $146 \mathrm{~kW} / \mathrm{m}^{2}$, a sharp increase in the wall superheat is measured, and a change in the heat transfer regime from nucleate boiling to film boiling is observed: The polished surface is shown blanketed by vapor at CHF in Fig. 5 (d). 
For experiments with the $3 \mathrm{~mm}$ particles, the polished copper surface is covered by a monolayer of 100 particles. The particles increase the heat transfer performance primarily by activating bubble nucleation from the narrow gap corners formed between the particles and the surface. The number of active nucleation sites increases as the heat flux increases, as clearly demonstrated in Fig. $6(\mathrm{a}, \mathrm{b})$. The addition of these $3 \mathrm{~mm}$ particles, and the resulting increase in active nucleation sites, lowers the wall superheat by $2.5-5 \mathrm{~K}$ compared to the polished surface at heat fluxes in the range of $8-38 \mathrm{~kW} / \mathrm{m}^{2}$, as shown in Fig. 3. However, the nucleate boiling heat transfer performance deteriorates as the heat flux reaches $\sim 40 \mathrm{~kW} / \mathrm{m}^{2}$, and underperforms the polished surface above this heat flux. At $51 \mathrm{~kW} / \mathrm{m}^{2}$, film boiling begins in the $3 \mathrm{~mm}$ particulate later, as identified in Fig. 3 by a sharp increase in the wall superheat. The reduction in CHF for millimeter-sized particles is attributed to inefficient vapor escape and liquid replenishment counterflow caused by the dense packing of particles on the surface. Compared to the polished surface, the flow resistance to vapor escaping from the surface and to liquid returning to the cavities where it is vaporized is greater.

Introduction of smaller free particles having sizes of several hundreds of micrometers onto the heated surface facilitates bubble nucleation at a low wall superheat and improves nucleate boiling heat transfer more significantly than the millimeter-sized particles. The three different test cases using $3 \mathrm{~g}$ each of 0.8 $2 \mathrm{~mm}, 0.6-0.8 \mathrm{~mm}$, and 149-440 $\mu \mathrm{m}$ particle size ranges demonstrate similar boiling curve trends in Fig. 3. Fig. 6 (c, e, and g) show that these three particle size ranges lead to uniform nucleate boiling over the heated surface at low heat fluxes. Each of these cases shows a higher heat transfer coefficient than the polished surface in Fig. 4 up to heat fluxes of around 80, 95, and $70 \mathrm{~kW} / \mathrm{m}^{2}$, respectively.

Since the particles are not fixed to the heated surface, they migrate along the surface and the particlelayer thickness varies dynamically due to the surrounding fluid flow patterns. The particle motion causes slight differences in boiling curve trends for each size range with increasing heat flux. The 0.8-2 mm particles, being the heaviest, remain on the surface even at high heat fluxes; however, the particles do aggregate at some parts of the heated surface, exposing portions of the polished surface to the working fluid, as shown in Fig. 6 (d). This behavior is expected because $3 \mathrm{~g}$ of $0.8-2 \mathrm{~mm}$ particles covers only approximately $75 \%$ of the surface when initially placed on the surface. Over the areas where the underlying polished surface is exposed, nucleation is suppressed, and the mechanism of heat transfer changes to free convection. This less-effective heat transfer mechanism causes the boiling curve and the $h-q$ curve for the $0.8-2 \mathrm{~mm}$ particles to deviate from the $0.6-0.8 \mathrm{~mm}$ and $149-440 \mu \mathrm{m}$ particle size cases. For the intermediate particle size range, $3 \mathrm{~g}$ of $0.6-0.8 \mathrm{~mm}$ particles cover the entire surface, and boiling is maintained over the entire surface without noticeable particle redistribution, as shown in Fig. 6 (f). Despite covering the entire surface when settled, Fig. 6 (h) shows that the lightest $149-440 \mu \mathrm{m}$ particles 
are easily moved around on the surface by bulk fluid motion and agglomerate near the center of the heated surface. As a result, two corners of the polished heated surface are exposed directly to the working fluid, and boiling is suppressed over these areas. For this reason, among these particle size groups with the same total weight of $3 \mathrm{~g}$, the $0.6-0.8 \mathrm{~mm}$ particles show the greatest average improvement in boiling heat transfer up to a heat flux $\sim 100 \mathrm{~kW} / \mathrm{m}^{2}$. The measured CHF values for the $0.8-2 \mathrm{~mm}, 0.6-0.8 \mathrm{~mm}$, and $149-440 \mu \mathrm{m}$ particle groupings are 87,115 , and $102 \mathrm{~kW} / \mathrm{m}^{2}$, respectively. This corresponds to 60, 79, and $70 \%$ of the $\mathrm{CHF}$ for the polished surface, with the reduction being attributed to the liquid replenishment counterflow resistance at the nucleation sites as described for the millimeter-size particles.

When the size of free particles is further decreased to $10 \mu \mathrm{m}$, the particle size falls significantly below the observed bubble departure diameter, and each particle does not provide a unique nucleation site. Thus, nucleate boiling does not occur over the entire surface with $0.6 \mathrm{~g}$ of $10 \mu \mathrm{m}$ particles at low heat fluxes; instead, several nucleation sites activate over the surface. Rising vapor locally displaces the 10 $\mu \mathrm{m}$ particulate layer, and the bubble departure diameter at each of these nucleation sites is qualitatively larger than for any other particle size tests, as shown in Fig. 7 (a). As the heat flux is increased to 10.5 $\mathrm{kW} / \mathrm{m}^{2}$, the nucleation sites extend over a larger area, and pull particles neighboring the nucleation site away from the surface along with the rising vapor, resulting in improved nucleate boiling by means of large, stable vapor columns, as illustrated in the visualization in Fig. 7 (b). This nucleate boiling behavior that occurs at each enlarged nucleation site enhances boiling heat transfer compared to all previous test cases, and a steep slope in the boiling curve is observed for the heat fluxes above $10.5 \mathrm{~kW} / \mathrm{m}^{2}$ (Fig. 3). At the particle loading of $0.6 \mathrm{~g}$ for this particle size, the wall superheat is maintained below $20 \mathrm{~K}$ until CHF is reached. Critical heat flux occurs at a heat flux of $123 \mathrm{~kW} / \mathrm{m}^{2}$, corresponding to $84 \%$ of the polished surface value. This is in contrast to fixed porous coatings, which have been shown to increase CHF compared to a polished surface [3,14]; for such fixed coatings, this improvement is attributed to capillaryassisted liquid replenishment in a thin layer that does not impede vapor escape [2]. The decreased CHF compared to a smooth surface may then be due to a lack of capillary resupply in the free-particle layer or the result of the large quantity of particles that are observed to stay in contact with the surface up to CHF, hindering liquid replenishment to the surface.

At the extreme in the particle size range, when nanoscale particles are used, little effect is observed on the nucleate boiling heat transfer performance of FC-72. The polished surface, when covered with 0.2 $\mathrm{g}$ of 20-40 nm free particles, maintains marginally lower wall superheats compared to the polished surface without free particles across the entire range of heat fluxes. Several nucleation sites are formed that displace particles in a similar manner as with the $10 \mu \mathrm{m}$ sized particles. At a heat flux of $5.0 \mathrm{~kW} / \mathrm{m}^{2}$, nucleation sites are active at the upper right and lower right corners in the image of the heated surface 
viewed in Fig. 7 (c). Particles near the lower left corner in this image have moved toward the center of the heated surface due to bulk fluid flow, and do not provide active nucleation sites, as was the case with the 149-440 $\mu \mathrm{m}$ particles (Fig. $6(\mathrm{~h})$ ). As the heat flux increases to $9.4 \mathrm{~kW} / \mathrm{m}^{2}$, the fluid becomes translucent due to the increased quantity of suspended nanoscale particles, as shown in Fig. 7 (d). In contrast to the $10 \mu \mathrm{m}$ and larger particles that remain on the surface up to CHF, the nanoscale particles are completely suspended in the fluid, and increase CHF to $153 \mathrm{~kW} / \mathrm{m}^{2}$. This represents a $5 \%$ improvement compared to the polished surface. Several explanations for CHF enhancement due to nanoparticles are offered in the literature. One proposed phenomenon is a deposition of nanoparticles onto the heated surface to form a thin porous layer during boiling that increases CHF [23,28]. However, such a buildup of a porous structure was not observed in the present study. Instead, the slight improvement in CHF in this work is likely caused by the change in the wettability of the working fluid due to the nanoscale particles as discussed in [23,37].

\subsection{Effect of the number of free particles}

Results presented in the previous section generally indicate that the introduction of free particles on a heated surface can improve nucleate boiling heat transfer coefficient of a wetting fluid like FC-72, while CHF typically decreases in the cases where the free particles remain on the surface even at high heat fluxes, restricting vapor release and liquid replenishment. The effect of the number of free particles on the heated surface on nucleate boiling heat transfer coefficients and CHF using FC-72 is now investigated. Fig. 8 and Fig. 9 present the boiling curves and the corresponding heat transfer coefficients for different quantities of a given free particle size $(10 \mu \mathrm{m}, 149-440 \mu \mathrm{m}$, and $0.6-0.8 \mathrm{~mm})$.

As a general trend for all particle sizes tested, the nucleate boiling heat transfer coefficient increases with an increasing number of particles at low heat fluxes after the onset of nucleate boiling. For example, $3 \mathrm{~g}$ of the $0.6-0.8 \mathrm{~mm}$ and $149-440 \mu \mathrm{m}$ free particle groupings, representing the largest loading for both size ranges, exhibit lower wall superheats for heat fluxes below $87 \mathrm{~kW} / \mathrm{m}^{2}$ and $54 \mathrm{~kW} / \mathrm{m}^{2}$, respectively. For the lowest quantity considered of the $149-440 \mu \mathrm{m}$ particles, introduction of $0.6 \mathrm{~g}$ of particles yields the lowest heat transfer coefficient up to a heat flux of $67 \mathrm{~kW} / \mathrm{m}^{2}$. This implies that increasing the number of free particles on the heated surface increases the number of contact points and thus activates a greater number of nucleation sites for boiling. The increased nucleation site density improves the nucleate boiling heat transfer performance.

A second reason for the increase in performance with particle loading is due to the number of free particles that remain in contact with the surface. For the sub-millimeter particle sizes described in Fig. 8, unlike the larger millimeter-sized particles that stay on the surface, it is observed that the particles are 
pulled away from the surface by buoyant vapor that departs from the surface. When a smaller number of particles is used, the surface may locally be stripped of particles and the boiling suppressed, whereas a comparatively higher particle loading may allow such areas to be immediately fed by other loose particles.

While increasing the number of particles increases the heat transfer coefficient at intermediate heat fluxes, reducing the number of free particles mitigates the CHF reduction compared to a polished surface. When $3 \mathrm{~g}$ of $149-440 \mu \mathrm{m}$ particles are introduced as free particles, the heated surface is covered by a 1 mm-thick layer of particles. This layer hinders vapor escape form the surface, and a transition to film boiling occurs at a heat flux of $102 \mathrm{~kW} / \mathrm{m}^{2}$, a value that is $70 \%$ of the polished-surface critical heat flux. The particles fall to the heated surface in the vapor space at CHF, as shown in Fig. 6 (i). For this particular case, an even distribution of particles at CHF indicates that the vapor film covers the entire surface. Vapor escape from this vapor-particle layer is observed intermittently in the videos acquired. In comparison, reduced 149-440 $\mu \mathrm{m}$ particle quantities of $0.6 \mathrm{~g}$ and $1 \mathrm{~g}$ yield CHF values that are identical to that of the polished surface $\left(146 \mathrm{~kW} / \mathrm{m}^{2}\right)$ at a similar wall superheat of approximately $35 \mathrm{~K}$. For these cases, most particles stay near the surface; however, their positions continuously move about the surface due to the bulk liquid/vapor motion, and some fraction of the particles are entrained in the fluid at CHF. It is hypothesized that this spontaneous movement of particles prevents clogging of vapor at the surface, and yields a similar CHF to that of the polished surface.

These trends for the $149-440 \mu \mathrm{m}$ particles in regard to the effect of the number of particles are also preserved for the $0.6-0.8 \mathrm{~mm}$ particles. When the quantity of particles is decreased from $3 \mathrm{~g}$ to $1 \mathrm{~g}$, the measured heat transfer coefficients decreases below heat fluxes of $86 \mathrm{~kW} / \mathrm{m}^{2}$; yet, CHF increases from $115 \mathrm{~kW} / \mathrm{m}^{2}$ to $141 \mathrm{~kW} / \mathrm{m}^{2}$.

Among all the experiments conducted with free particles in this work, $0.2 \mathrm{~g}$ of the $10 \mu \mathrm{m}$ particles showed the greatest improvement in boiling of FC-72 over a wide range of heat fluxes, from 20 to 160 $\mathrm{kW} / \mathrm{m}^{2}$. The boiling phenomena observed for this case are very similar to the observations described earlier with $0.6 \mathrm{~g}$ of these particles. As described in section 4.1, the mechanism of nucleation-site formation is unique at this particle size, and larger vapor columns are formed over the surface at locations where particles are pulled away from the surface by the rising vapor, as shown in Fig. 7 (a, b). Therefore, in contrast to the preceding conclusions drawn about the larger particle sizes, the smaller particle loading of $0.2 \mathrm{~g}$ of the $10 \mu \mathrm{m}$ particles is observed to generate vapor columns over a larger portion of the surface than for the higher loading of $0.6 \mathrm{~g}$. This results in higher heat transfer coefficients. Likewise, $0.2 \mathrm{~g}$ of the $10 \mu \mathrm{m}$ particles increases CHF compared to the polished surface by $10 \%$, the largest improvement observed in the present study (Table 1). This increase in CHF for the lower particle loading of $0.2 \mathrm{~g}$ compared to $0.6 \mathrm{~g}$ for the $10 \mu \mathrm{m}$ particles is similar to the trend described for $149-440 \mu \mathrm{m}$ and $0.6-0.8 \mathrm{~mm}$ 
particles described above. The improvement in CHF by addition of microscale free particles has not been studied previously, and further investigation of the boiling process under these conditions is required to identify the enhancement mechanism, such as changes in the liquid properties.

In order to make generalized comparisons across a range of heat fluxes versus the baseline polished surface without free particles, the average percentage enhancement in nucleate boiling heat transfer coefficient is quantified using

$$
\frac{\sum_{i=1}^{n} \frac{\left(h_{i}-h_{p, i}\right)}{h_{p, i}}\left(q_{i}^{\prime \prime}-q_{i-1}^{\prime \prime}\right) \times 100}{q_{n}^{\prime \prime}-q_{i-1}^{\prime \prime}},
$$

where $h_{i}$ and $h_{p, i}$ are the heat transfer coefficients of the experimental case and the polished surface baseline case at each heat flux, for $n$ data points. In order to compare over a continuous range of heat fluxes, $h_{p, i}$ is obtained from a polynomial fit of the polished $h-q^{\prime \prime}$ curve, given as

$$
h_{p, i}=0.018+0.044 q_{i}^{\prime \prime}-0.0098 \times 10^{-2} q_{i}^{\prime \prime 2} .
$$

The improvement in nucleate boiling due to $0.2 \mathrm{~g}$ of the $10 \mu \mathrm{m}$ free particles is evaluated using this parameter to be $76.3 \%$ compared to the case of polished surface over the heat flux range of 10 to 159 $\mathrm{kW} / \mathrm{m}^{2}$. This is in contrast to the least effective test case, in which one-hundred $3 \mathrm{~mm}$ free particles are introduced, which shows only a $7.2 \%$ improvement over the heat flux range of $10-50 \mathrm{~kW} / \mathrm{m}^{2}$. The nucleate boiling heat transfer enhancement calculated for all free particle sizes and quantities is presented in Table 1. The percentage enhancement is calculated for a range of $10 \mathrm{~kW} / \mathrm{m}^{2}$ to the maximum heat flux tested in each experimental case.

\subsection{Effect of working fluid properties}

The results obtained in the present study for the wetting fluid FC-72 differ from the behavior observed with water in a companion paper [38]. While the trend of variation with particle size is similar, the optimum particle size at which the nucleate boiling heat transfer coefficient is maximized is significantly smaller for FC-72, on the order tens of microns. In contrast, a particle size of $3 \mathrm{~mm}$ is shown to be optimal for water at low heat fluxes near the onset of nucleate boiling, while $6 \mathrm{~mm}$ particles show the best heat transfer performance at high heat fluxes. Millimeter-size particles show little effect on the nucleate boiling heat transfer coefficient for FC-72 (Fig. 10), and result in a decrease in CHF (Table 1). This difference in the optimum particle size is attributable to the differences in surface tension; FC-72 is a highly wetting fluid, with a low surface tension of $0.010 \mathrm{~N} / \mathrm{m}$ at $25{ }^{\circ} \mathrm{C}$ [Error! Bookmark not defined.], versus $0.072 \mathrm{~N} / \mathrm{m}$ for water [39]. Thus, smaller cavities would be expected to be preferred for nucleation in FC-72. Based on the results of the present study and those in [38], it is found that the effect 
of wetting holds true for the free particle technique, for which narrow corner cavities formed between the free particles and the heated surface serve as nucleation sites.

\section{Conclusions}

In the present study, the concept of a free-particle boiling heat transfer enhancement technique is proposed and experimentally investigated using FC-72 as the working fluid. A series of experiments were conducted to investigate the effect of copper particle size and number on boiling heat transfer coefficient and critical heat flux (CHF). The experimental results show that microscale free particles placed on a heated surface effectively facilitate bubble nucleation and thus enhance nucleate boiling heat transfer. However, placement of a large quantity of such particles on the heated surface significantly deteriorates CHF by increasing the resistance to vapor release and liquid replenishment under vigorous boiling conditions. An optimum particle size and quantity exists that improves nucleate boiling and increases CHF, identified to be $0.2 \mathrm{~g}$ of $10 \mu \mathrm{m}$ free particles for FC-72 in the current study. Due to the difference in working fluid properties, millimeter-size free particles which were identified as the optimum particle size for boiling of water in [38] show little improvement of nucleate boiling heat transfer in FC72 , and significantly reduce $\mathrm{CHF}$.

\section{Acknowledgements}

Funding for this work from the Cooling Technologies Research Center, an NSF I/UCRC at Purdue University, is gratefully acknowledged. 


\section{References}

[1] R. M. Milton, U.S. Pat. 3384154, 1968.

[2] S. G. Liter, M. Kaviany, Pool-boiling CHF enhancement by modulated porous-layer coating: theory and experiment, International Journal of Heat and Mass Transfer 44 (2001) 4287-4311.

[3] S. M. You, T. W. Simon, A. Bar-Cohen, A technique for enhancing boiling heat transfer with application to cooling of electronic equipment, IEEE Transactions on Components, Hybrids and Manufacturing Technology 15 (5) (1992) 823-831.

[4] J. P. O’Connor, S. M. You, A painting technique to enhance pool boiling heat transfer in saturated FC72, Journal of Heat Transfer 117 (1995) 387-393.

[5] M. S. El-Genk, J. L. Parker, Enhanced boiling of HFE-7100 dielectric liquid on porous graphite, Energy Conversion and Management 46 (2005) 2455-2481.

[6] J. L. Parker, M. S. El-Genk, Enhanced saturation and subcooled boiling of FC-72 dielectric liquid, International Journal of Heat and Mass Transfer 48 (2005) 3736-3752.

[7] A. E. Bergles, M. C. Chyu, Characteristics of nucleate pool boiling from porous metallic coatings, Journal of Heat Transfer 104 (1982) 279-285.

[8] V. I. Borzenko, S. P. Malyshenko, Mechanisms of phase exchange under conditions of boiling on surfaces with porous coatings, High Temperature 39 (5) (2001) 714-721.

[9] W. Nakayama, T. Daikoku, H. Kuwahara, T. Nakajima, Dynamic model of enhanced boiling heat transfer on porous surface - Part I: Experimental investigation, Journal of Heat Transfer 102 (1980) 451456.

[10] S. Murthy, Y. Joshi, S. Gurrum, W. Nakayama, Enhanced boiling heat transfer simulation from structured surfaces: Semi-analytical model, International Journal of Heat and Mass Transfer 49 (2006) $1885-1895$.

[11] L. H. Chai and D. S. Wen, Theoretical analyses on boiling critical heat flux with porous media, Heat and Mass Transfer 41 (2005) 780-784.

[12] C. Li, G. P. Peterson, Parametric study of pool boiling on horizontal highly conductive microporous coated surfaces, Journal of Heat Transfer 129 (11) (2007) 1465-1475.

[13] J. J. Wei, H. Honda, Effects of fin geometry on boiling heat transfer from silicon chips with micropin-fins immersed in FC-72, International Journal of Heat and Mass Transfer 46 (21) (2003) 4059-4070. 
[14] K. N. Rainey, S. M. You, Pool boiling heat transfer from plain and microporous, square pin-finned surfaces in saturated FC-72, Journal of Heat Transfer 122 (2000) 509-516.

[15] M. Jakob, Heat Transfer, John Wiley \& Sons, New York, 1949.

[16] H. M. Kurihari, J. E. Myers, Effects of superheat and roughness on the boiling coefficients, AlChE Journal 6 (1960) 83-91.

[17] B. J. Jones, J. P. McHale, S. V. Garimella, The influence of surface roughness on nucleate pool boiling heat transfer, Journal of Heat Transfer 131 (12) (2009) 121009.

[18] S. T. Hsu, F. W. Schmidt, Measured variations in local surface temperatures in pool boiling of water, Journal of Heat Transfer 83 (1961) 254-260.

[19] P. J. Marto, W. M. Rohsenow, Effects of surface conditions on nucleate pool boiling of sodium, Journal of Heat Transfer 88 (1966) 196-203.

[20] P. Griffith, J. D. Wallis, The role of surface conditions in nucleate boiling, Chemical Engineering Progress Symposium Series 56 (1960) 49-63.

[21] C. Corty, A. S. Foust, Surface variables in nucleate boiling, Chemical Engineering Progress Symposium Series 17 (1955) 1-12.

[22] S. B. White, A. J. Shih, K. P. Pipe, Effects of nanoparticle layering on nanofluid and base fluid pool boiling heat transfer from a horizontal surface under atmospheric pressure, Journal of Applied Physics 107 (2010) 114302.

[23] S. J. Kim, I. C. Bang, J. Buongiorno, L. W. Hu, Surface wettability change during pool boiling of nanofluids and its effect on critical heat flux, International Journal of Heat and Mass Transfer 50 (2007) 4105-4116.

[24] S. J. Kim, I. C. Bang, J. Buongiorno, L. W. Hu, Effects of nanoparticle deposition on surface wettability influencing boiling heat transfer in nanofluids, Applied Physics Letters 89 (15) (2006) 153107.

[25] H. S. Xue, J. R. Fan, R. H. Hong, Y. C. Hu, Characteristic boiling curve of carbon nanotube nanofluid as determined by the transient calorimeter technique, Applied Physics Letters 90 (18) (2007) 184107.

[26] K. J. Park, D. Jung, Enhancement of nucleate boiling heat transfer using carbon nanotubes, International Journal of Heat and Mass Transfer 50 (2007) 4499-4502. 
[27] D. Wen, Y. Ding, Experimental investigation into the pool boiling heat transfer of aqueous based $\gamma$ alumina nanofluids, Journal of Nanoparticle Research 7 (2005) 265-274.

[28] P. Vassallo, R. Kumar, S. D’Amico, Pool boiling heat transfer experiments in silica-water nanofluids, International Journal of Heat and Mass Transfer 47 (2004) 407-411.

[29] S. M. Kwark, M. Amaya, R. Kumar, G. Moreno, S. M. You, Effects of pressure, orientation, and heater size on pool boiling of water with nanocoated heaters, International Journal of Heat and Mass Transfer 53 (2010) 5199-5208.

[30] J. Li, P. Cheng, Bubble cavitation in a microchannel, International Journal of Heat and Mass Transfer 47 (2004) 2689-2698.

[31] Y.-Y. Hsu, On the size range of active nucleation cavities on a heating surface, Journal of Heat Transfer 84 (1962) 207-216.

[32] Y.-Y. Hsu, R.W. Graham, Transport Processes in Boiling and Two-Phase Systems, Hemisphere, Washington, DC, 1976.

[33] M. S. El-Genk, J. L. Parker, Nucleate boiling of FC-72 and HFE-7100 on porous graphite at different orientations and liquid subcooling, Energy Conversion and Management 49 (2008) 733-750.

[34] J. L. Parker, M. S. El-Genk, Effect of surface orientation on nucleate boiling of FC-72 on porous graphite, Journal of Heat Transfer 128 (2006) 1159-1175.

[35] W. Wu, J.-H. Du, X.-J. Hu, B.-X. Wang, Pool boiling heat transfer and simplified one-dimensional model for prediction on coated porous surfaces with vapor channels, International Journal of Heat and Mass Transfer 45 (2002) 1117-1125.

[36] 3M Corporation, 2000, Fluorinert Electronic Liquid FC-72 Product Information 98-0212-2308-0 (HB), Specialty Materials Division.

[37] S. M. You, J. H. Kim, K. H. Kim, Effect of nanoparticles on critical heat flux of water in pool boiling heat transfer, Applied Physics Letters 83 (16) (2003) 3374-3376.

[38] T. Y. Kim, S. V. Garimella, Investigation of boiling heat transfer in water using a free-particles-based enhancement technique, International Journal of Heat and Mass Transfer, (in review).

[39] J. A. Dean, Lange's Handbook of Chemistry, fifteenth ed., McGraw-Hill, New York, 1999. 
Table 1. Characteristics of the copper free-particle surface coatings used in the experiments.

\begin{tabular}{cccccc}
\hline Particle size & Quantity & $\begin{array}{c}\text { Estimated layer } \\
\text { thickness }\end{array}$ & $\begin{array}{c}\text { Surface } \\
\text { coverage }(\%)\end{array}$ & $\begin{array}{c}\text { CHF } \\
\left(\mathrm{kW} / \mathrm{m}^{2}\right)\end{array}$ & $\begin{array}{c}\text { Nucleate boiling } \\
\text { enhancement }(\%)\end{array}$ \\
\hline \multirow{2}{*}{$20-40 \mathrm{~nm}$} & $0.2 \mathrm{~g}$ & $\sim 57 \mu \mathrm{m}$ & 100 & 153 & 7.6 \\
\hline \multirow{2}{*}{$10 \mu \mathrm{m}$} & $0.2 \mathrm{~g}$ & $\sim 67 \mu \mathrm{m}$ & 100 & 160 & 76.3 \\
& $0.6 \mathrm{~g}$ & $\sim 181 \mu \mathrm{m}$ & 100 & 123 & 61.1 \\
\hline \multirow{2}{*}{$149-440 \mu \mathrm{m}$} & $0.6 \mathrm{~g}$ & $\sim 295 \mu \mathrm{m}$ & 71 & 146 & 7.7 \\
& $1 \mathrm{~g}$ & $\sim 535 \mu \mathrm{m}$ & 100 & 146 & 12.9 \\
\hline \multirow{2}{*}{$600-800 \mu \mathrm{m}$} & $1 \mathrm{~g}$ & $\sim 1020 \mu \mathrm{m}$ & 100 & 102 & 23.3 \\
\hline $0.8-2 \mathrm{~mm}$ & $3 \mathrm{~g}$ & $\sim 700 \mu \mathrm{m}$ & 50 & 141 & 13.0 \\
\hline $3 \mathrm{~mm}$ & $100 \mathrm{EA}$ & $\sim 1.4 \mathrm{~mm}$ & 75 & 87 & 23.7 \\
\hline $6 \mathrm{~mm}$ & $25 \mathrm{EA}$ & $6 \mathrm{~mm}$ & 100 & 51 & 7.2 \\
\hline $9 \mathrm{~mm}$ & $9 \mathrm{EA}$ & $9 \mathrm{~mm}$ & 100 & 119 & 3.5 \\
\hline $\begin{array}{c}\text { Polished } \\
\text { surface }\end{array}$ & N/A & N/A & N/A & 146 & 4.4 \\
\hline
\end{tabular}




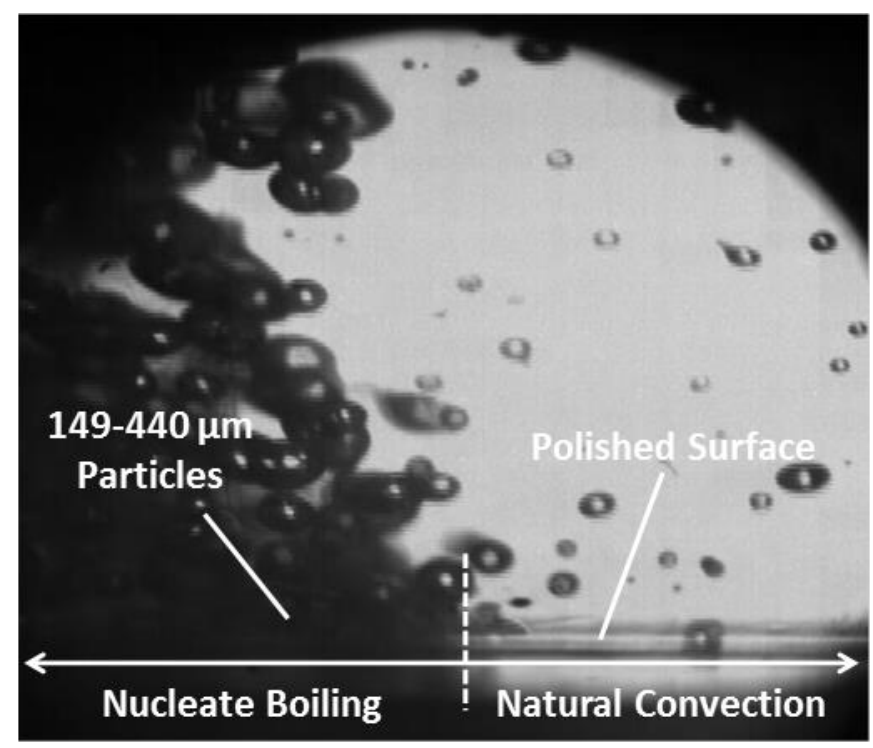

Fig. 1. Nucleate boiling characteristics of FC-72 from a heated surface covered by 149-440 $\mu \mathrm{m}$ copper free particles on the left, and polished on the right, at a heat flux of $10 \mathrm{~kW} / \mathrm{m}^{2}$. The related movie is available online as Supplementary Data. 


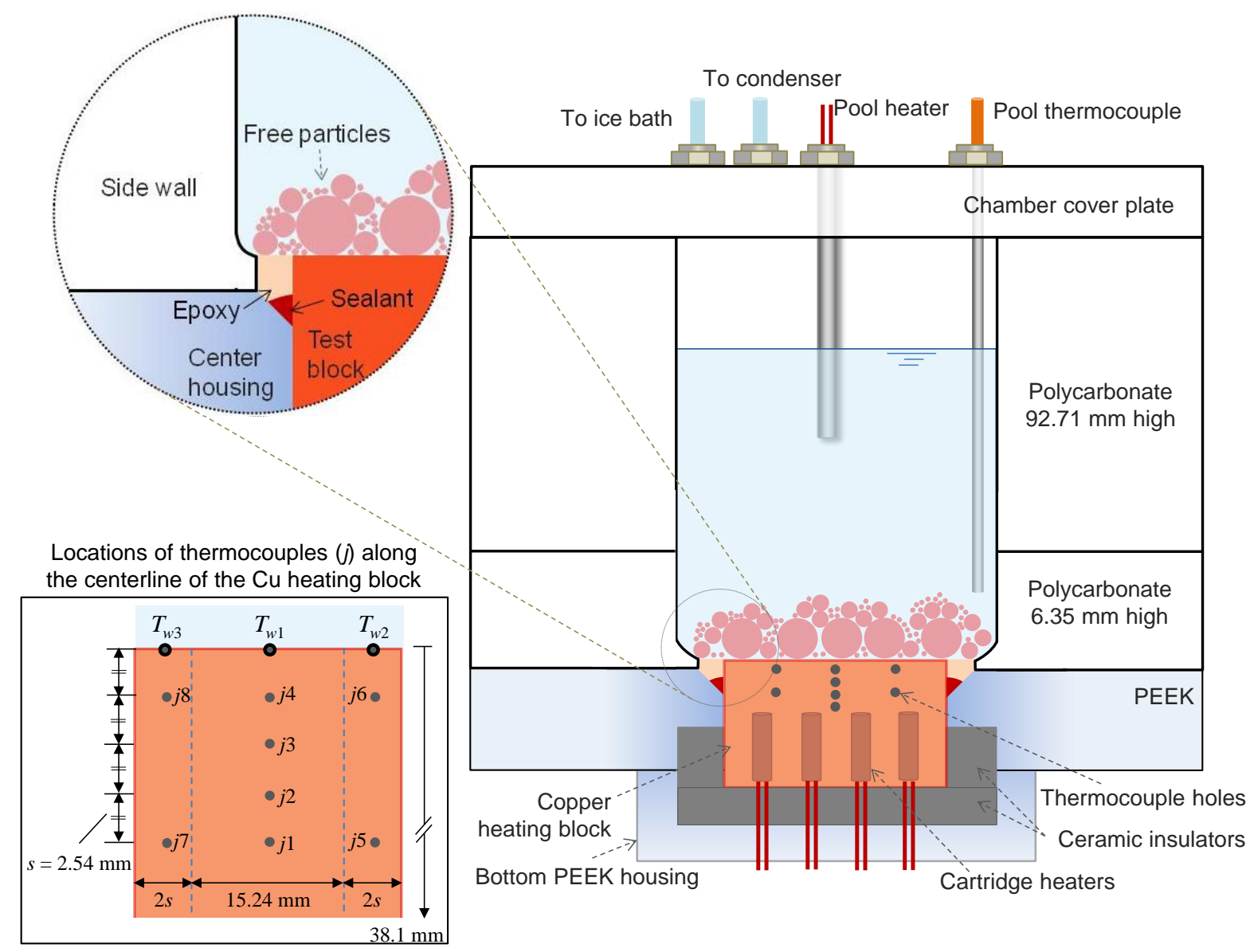

Fig. 2. Schematic diagram of the experimental facility and locations of the thermocouples in the copper heating block. 


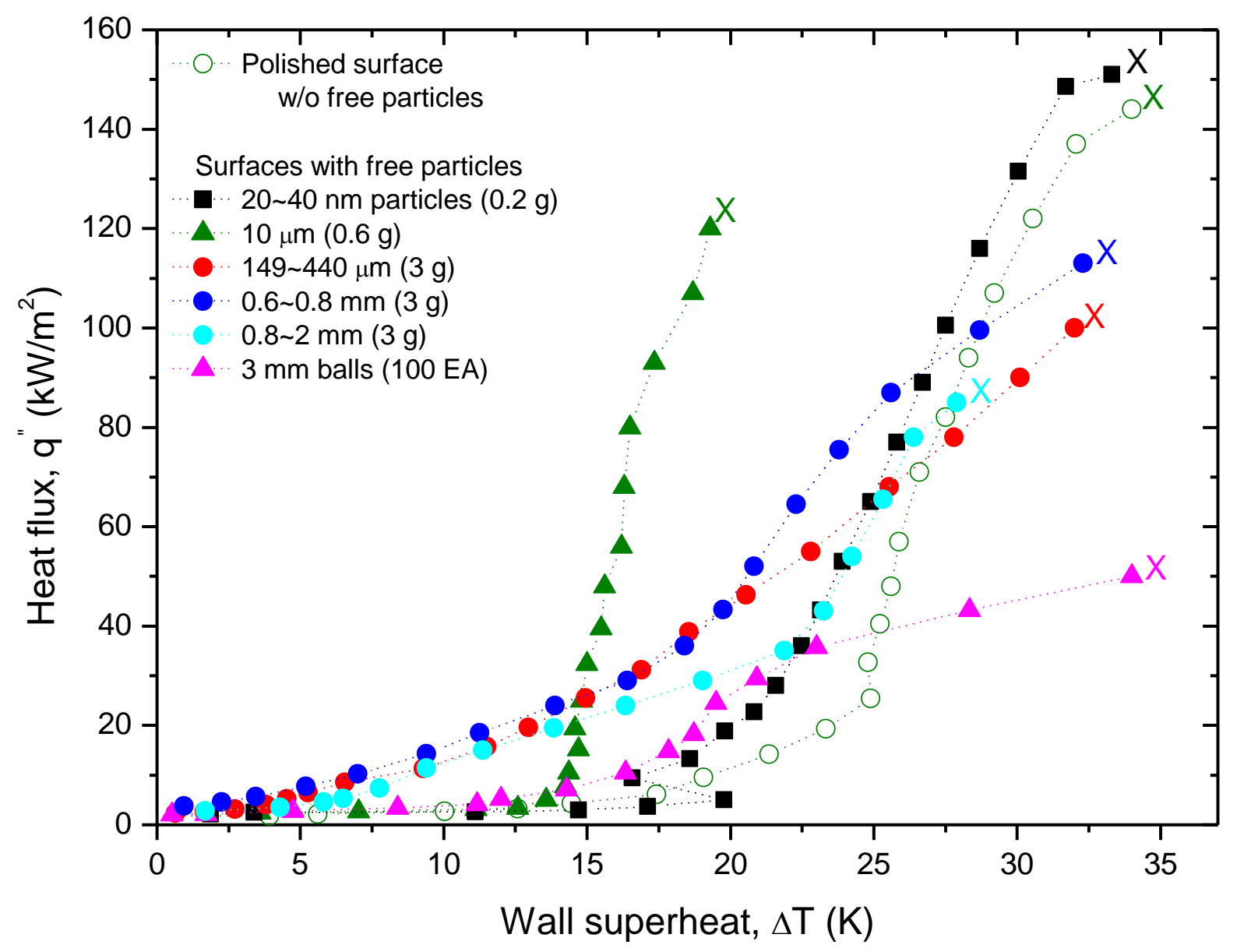

Fig. 3. Boiling curves for a range of free particle sizes. The point of critical heat flux is indicated by an "X" on the plot. 


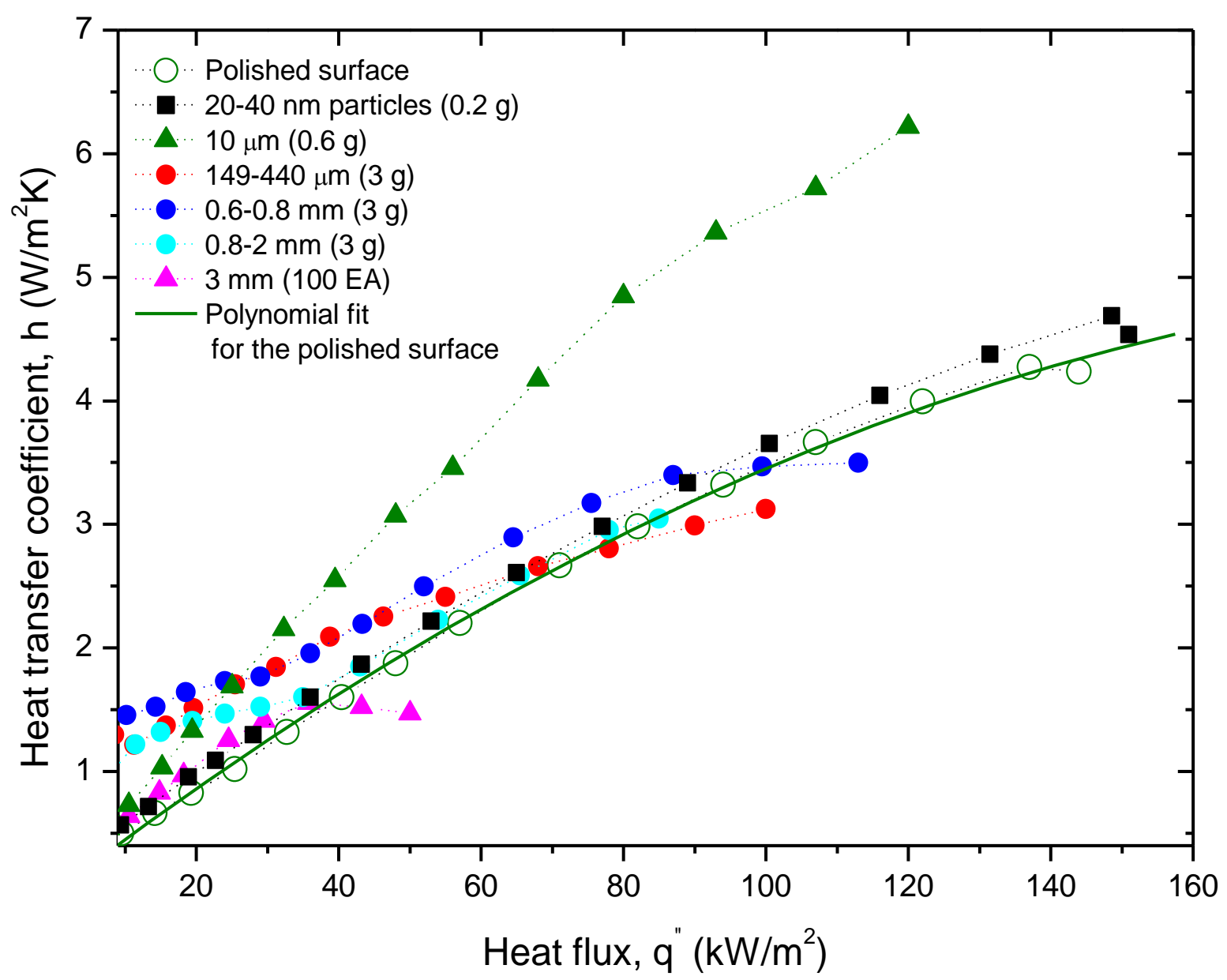

Fig. 4. Heat transfer coefficients as a function of heat flux for the same experimental cases as presented in Fig. 3. The dash-dotted line indicates a third-order polynomial fit to the polished surface data. 

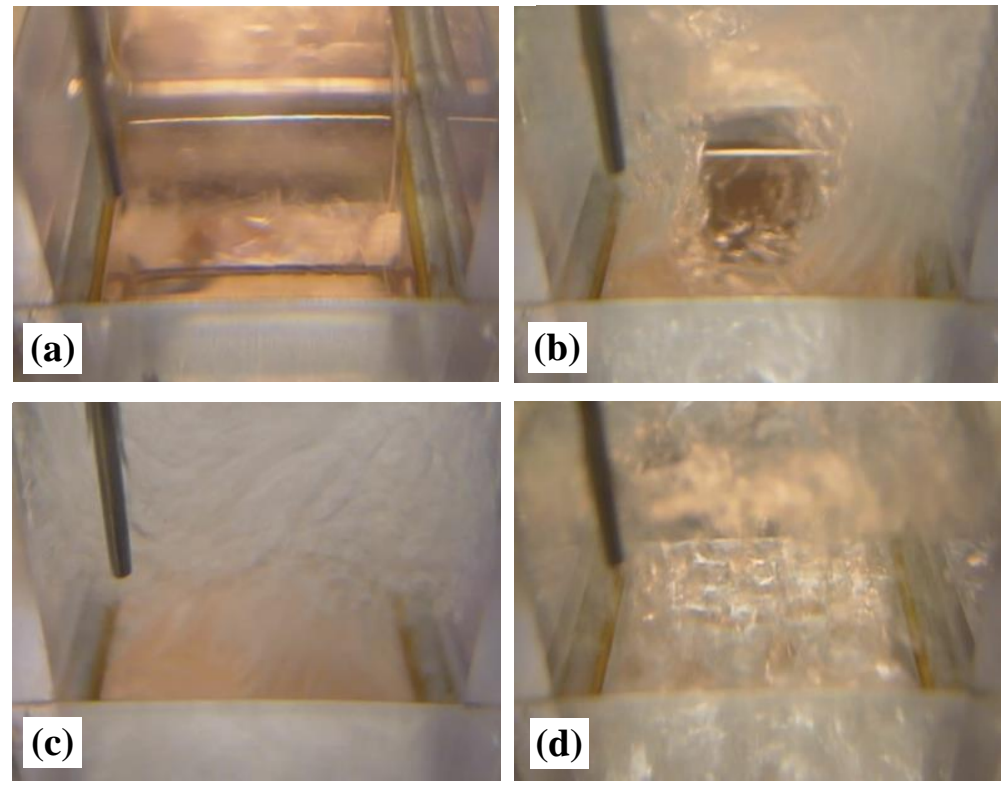

Fig. 5. Visualization of the boiling characteristics of FC-72 from the polished surface without free particles at (a) $2.2 \mathrm{~kW} / \mathrm{m}^{2}$, (b) $33 \mathrm{~kW} / \mathrm{m}^{2}$, (c) $71 \mathrm{~kW} / \mathrm{m}^{2}$, and (d) $146 \mathrm{~kW} / \mathrm{m}^{2}$. 

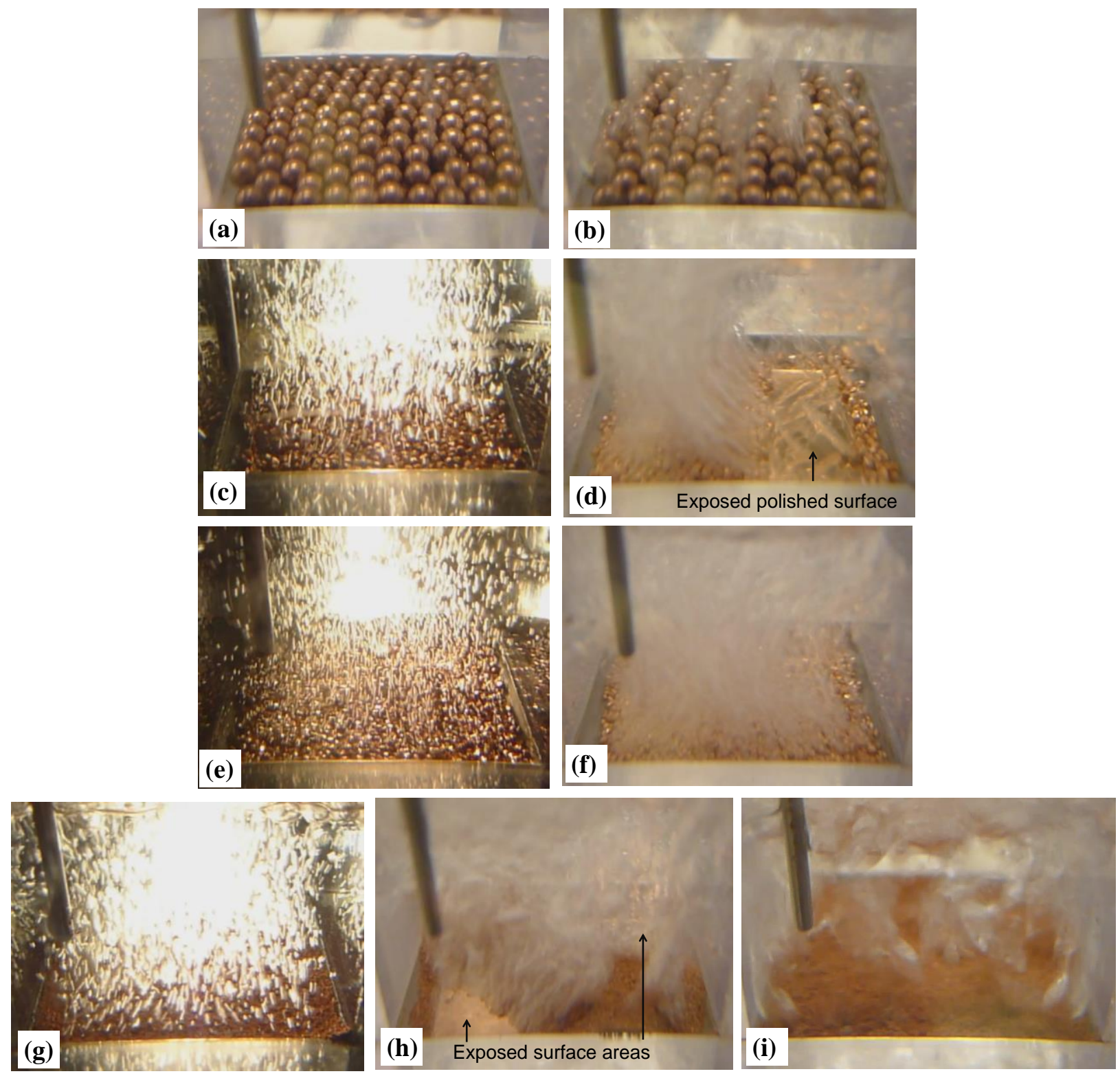

Fig. 6. Visualization of the boiling characteristics of FC-72 from the heated surface with different freeparticle loading conditions: one hundred $3 \mathrm{~mm}$ particles at (a) $3.4 \mathrm{~kW} / \mathrm{m}^{2}$ and (b) $15 \mathrm{~kW} / \mathrm{m}^{2} ; 3 \mathrm{~g}$ of $0.8-2$ mm particles at (c) $4.6 \mathrm{~kW} / \mathrm{m}^{2}$ and (d) $24 \mathrm{~kW} / \mathrm{m}^{2} ; 3 \mathrm{~g}$ of 0.6-0.8 mm particles at (e) $5.7 \mathrm{~kW} / \mathrm{m}^{2}$ and (f) 24 $\mathrm{kW} / \mathrm{m}^{2}$; and $3 \mathrm{~g}$ of $149-440 \mu \mathrm{m}$ particles at (g) $6.5 \mathrm{~kW} / \mathrm{m}^{2}$, (h) $26 \mathrm{~kW} / \mathrm{m}^{2}$, and (i) $102 \mathrm{~kW} / \mathrm{m}^{2}$ (CHF). A light source is turned on for acquisition of the images in (c), (e) and (g) to better visualize the tiny vapor bubbles. Arrows in (d) and (h) indicate exposed areas of the substrate from which free particles have been swept away; boiling is suppressed on the polished copper surface over these areas at the heat fluxes shown. 

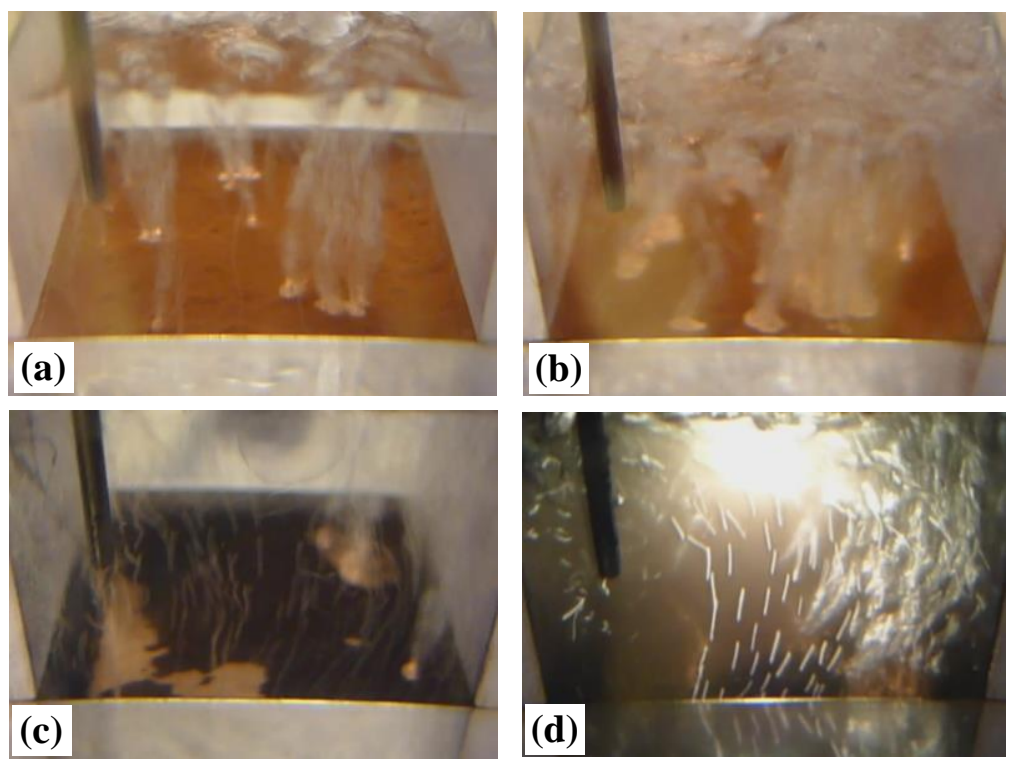

Fig. 7. Visualization of the boiling characteristics of FC-72 from the heated surface with $0.6 \mathrm{~g}$ of $10 \mu \mathrm{m}$ particles at (a) $5.0 \mathrm{~kW} / \mathrm{m}^{2}$ and (b) $10.5 \mathrm{~kW} / \mathrm{m}^{2}$, and with $0.2 \mathrm{~g}$ of $20-40 \mathrm{~nm}$ particles at (c) $5.0 \mathrm{~kW} / \mathrm{m}^{2}$ and (b) $9.4 \mathrm{~kW} / \mathrm{m}^{2}$. A light source is turned on for acquisition of the image in (d) due to the working fluid translucency imparted by the suspended nanoscale particles. 


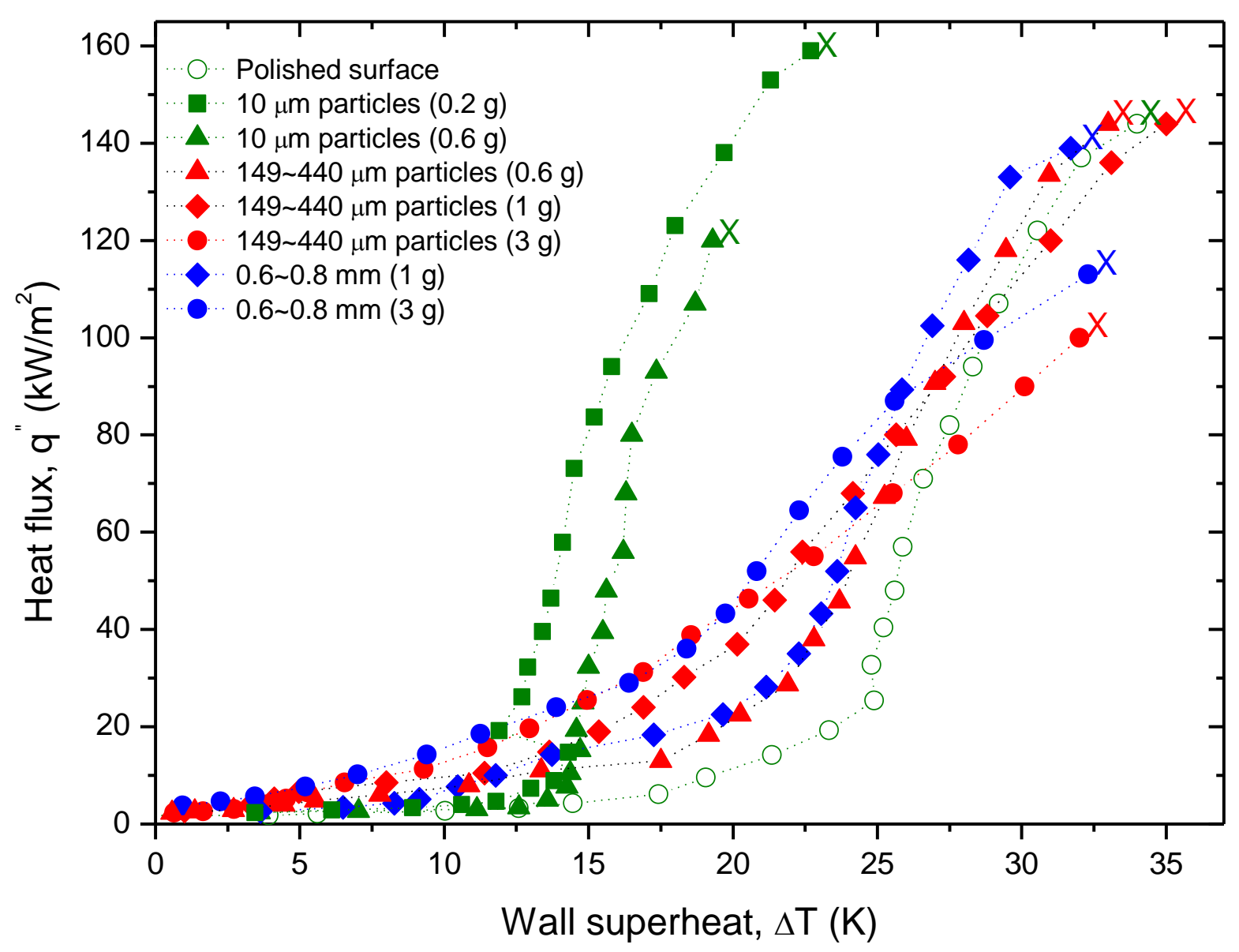

Fig. 8. Boiling curves for variable quantities of free particles of a given size. The point of critical heat flux is indicated by an " $X$ " on the plot. 


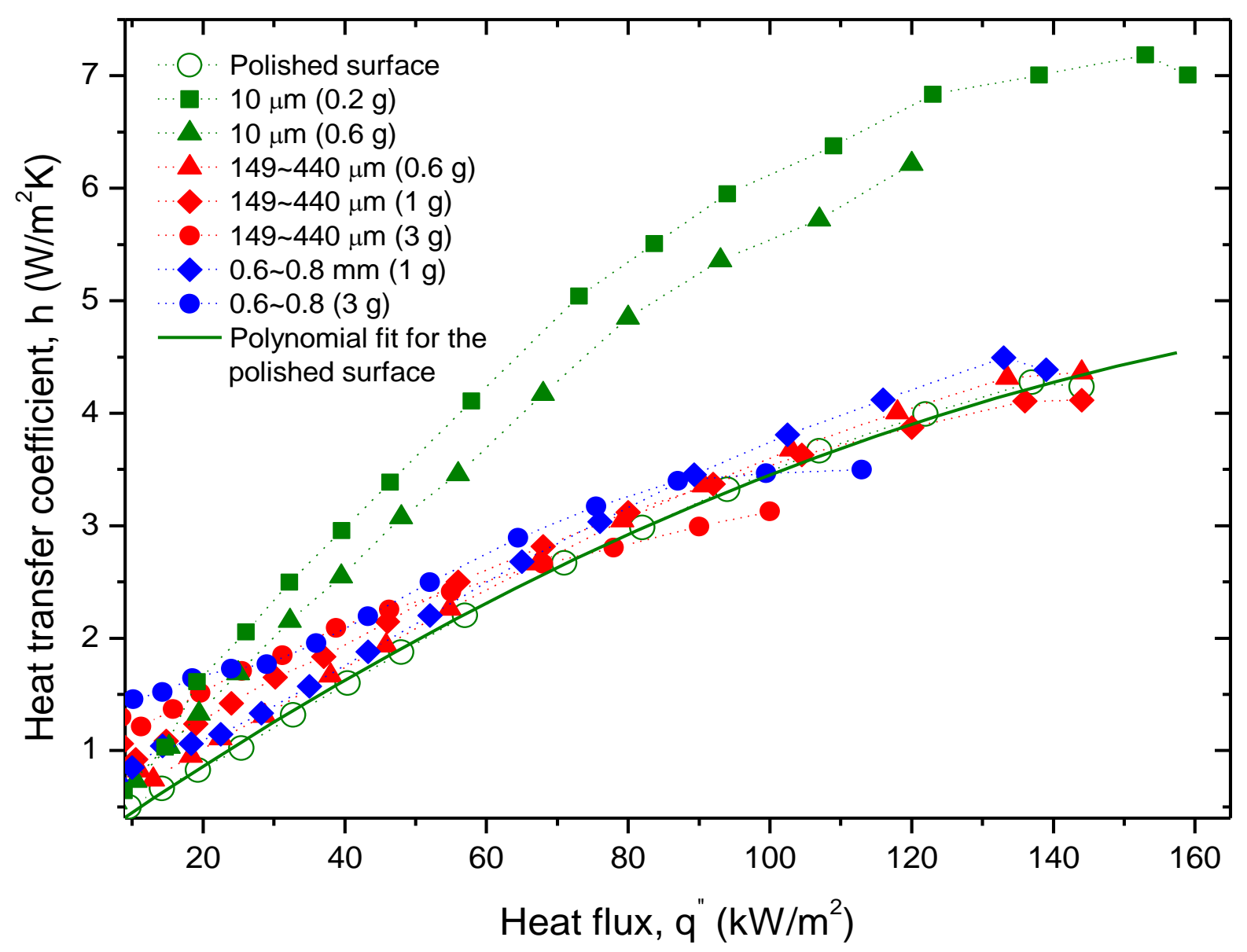

Fig. 9. Heat transfer coefficient as a function of heat flux for the same experimental cases presented in Fig. 8. 


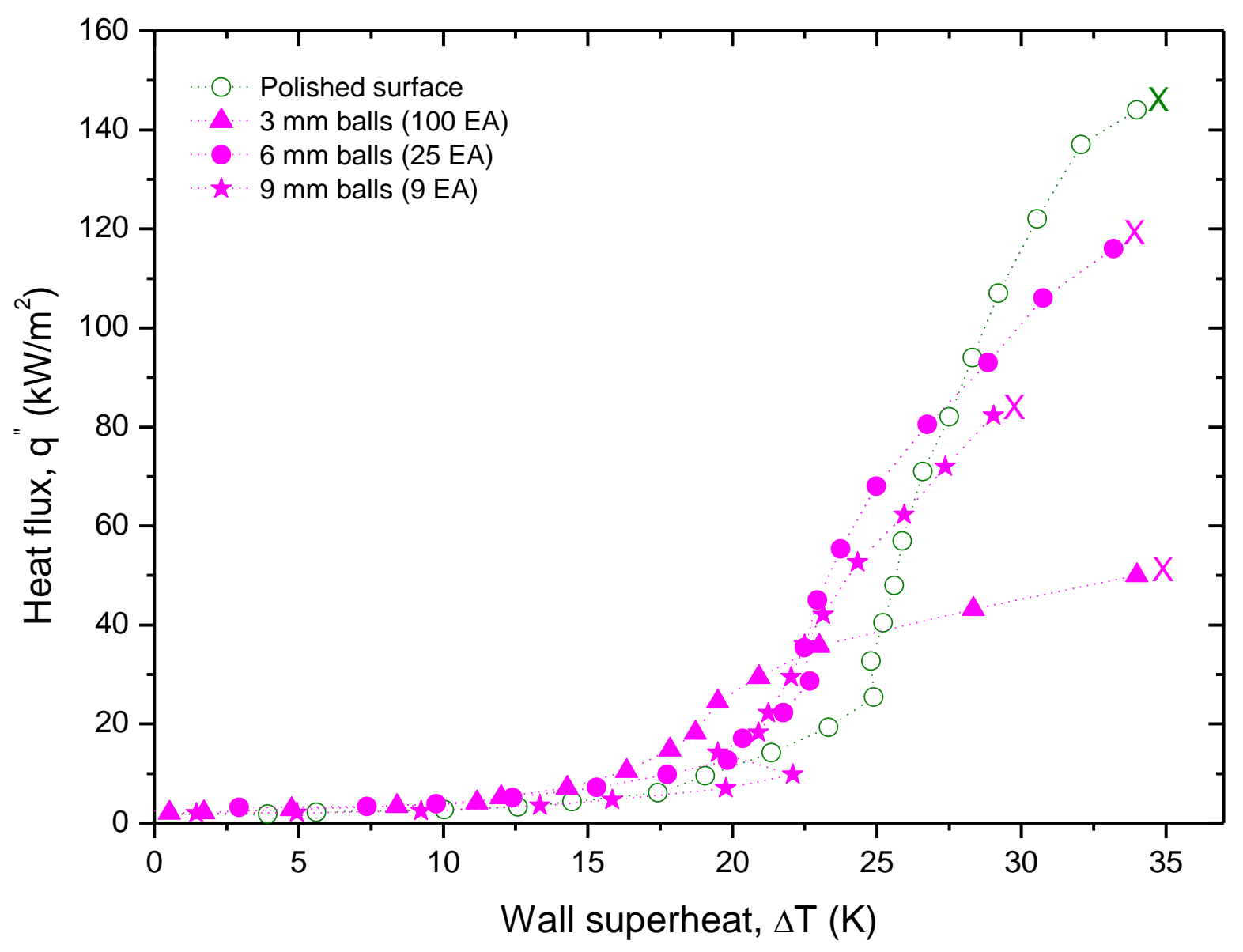

Fig. 10. Boiling curves for the experiments performed with the millimeter-sized free particles. 